\title{
Tumour necrosis factor-alpha expression in tumour islets confers a survival advantage in non-small cell lung cancer
}

\author{
Chandra M Ohri*1,2, Aarti Shikotra1,2, Ruth H Green¹, David A Waller ${ }^{3}$ and Peter Bradding 1,2
}

\begin{abstract}
Background: The role of TNFa in cancer is complex with both pro-tumourigenic and anti-tumourigenic roles proposed. We hypothesised that anatomical microlocalisation is critical for its function.

Methods: This study used immunohistochemistry to investigate the expression of TNFa in the tumour islets and stroma with respect to survival in 133 patients with surgically resected NSCLC.

Results: TNFa expression was increased in the tumour islets of patients with above median survival (AMS) compared to those with below median survival $(B M S)(p=0.006)$, but similar in the stroma of both groups. Increasing tumour islet TNFa density was a favorable independent prognostic indicator $(p=0.048)$ while stromal TNFa density was an independent predictor of reduced survival $(p=0.007)$. Patients with high TNFa expression (upper tertile) had a significantly higher 5 -year survival compared to patients in the lower tertile ( $43 \%$ versus $22 \%, p=0.01$ ). In patients with AMS, $100 \%$ of $\mathrm{TNFa}^{+}$cells were macrophages and mast cells, compared to only $28 \%$ in the islets and $50 \%$ in the stroma of BMS patients $(p<0.001)$.

Conclusions: The expression of TNFa in the tumour islets of patients with NSCLC is associated with improved survival suggesting a role in the host anti-tumour immunological response. The expression of TNFa by macrophages and mast cells is critical for this relationship.
\end{abstract}

\section{Background}

Non-small cell lung cancer (NSCLC) is the world's leading cause of cancer related death. At present, the majority of patients present with advanced stages of disease which are not amenable to curative treatment. Even with the optimal presentation of stage Ia disease, the 5-year survival is just $67 \%$ [1] assuming fitness for surgical resection. Currently chemotherapy does not offer cure for patients with NSCLC. Thus, it is vital that new biomarkers of disease and novel therapies are developed. It is now recognised that inflammatory and immune responses play a key role in cancer development and prevention $[2,3]$ and it hoped that manipulation of these may yield novel therapies in the future.

Tumour necrosis factor-alpha (TNF $\alpha)$ is a key and proximal component of many inflammatory pathways. It

*Correspondence: cohri@doctors.org.uk

1 Institute for Lung Health, Glenfield Hospital, Leicester, UK

Full list of author information is available at the end of the article plays a key role in host defence to a variety of pathogens $[4,5]$, but is also implicated in the promotion of many inflammatory diseases [6,7], including rheumatoid arthritis and inflammatory bowel disease.

The tumour biology of TNF $\alpha$ however is complicated, with evidence of both pro-tumourigenic and antitumourigenic activity in animal models $[8,9]$. Perhaps the best evidence that the predominant role played by TNF $\alpha$ is anti-tumourigenic arises from studies of anti-TNF $\alpha$ strategies for the treatment of inflammatory disease in man. These show a significant increase in the rate of neoplastic disease in patients receiving active treatment, and no evidence of protection against cancer development [10-16]. The complete resolution of NSCLC in a patient following withdrawal of anti-TNFa therapy is also described [17]. In contrast, the administration of antiTNF $\alpha$ has had no significant effect on the progression of several advanced cancers [18-20]. Furthermore, recombi- 
nant TNF $\alpha$ is a useful and licensed adjunctive treatment for sarcoma and melanoma [21,22].

There is therefore debate as to whether or not TNF $\alpha$ plays a role in NSCLC tumour cytotoxicity or conversely, tumour progression. Two small studies investigated previously the mRNA or protein expression of TNF $\alpha$ in NSCLC, and suggested overall that TNF $\alpha$ expression was either mildly beneficial but not an independent factor [23] or neutral [24], respectively. However, the anatomical localisation of the TNF $\alpha$ expressed was not taken into account. We have shown previously that the site of inflammatory cell infiltration in NSCLC is critical in terms of prognosis. Patients with high expression of macrophages in the tumour islets have extended survival independently of tumour stage, and these macrophages demonstrate high expression of TNF $\alpha$ and other cytotoxic markers, suggesting they are of an anti-tumourigenic cytotoxic M1 macrophage phenotype [25,26].

This previous work investigating TNFo expression in macrophages was aimed primarily at determining the phenotype of these cells rather than the prognostic significance of TNF $\alpha$ expression. Due to the nature of the work, relatively small numbers of patients were studied. The aim of this study was therefore to assess the prognostic significance of TNF $\alpha$ expression, irrespective of cell type in NSCLC, paying particular attention to its anatomical microlocalisation, in surgically resected NSCLC in our complete cohort of patients described previously [26].

\section{Methods}

Study Population

The study was approved by the Leicestershire Research Ethics Committee. The tissue specimens evaluated were from patients with NSCLC who had undergone resection with curative intent at the University Hospitals of Leicester National Health Service Trust (Leicester, United Kingdom). These patients had resections during two periods one dating from 1991 to 1994 and the second from January to December 1999. This cohort of patients has been described previously [26]. Of note, due to exhaustion of tumour tissue, 133 patient samples with $>60$ day survival post surgery were available for analysis in this study. Of the 133 patients studied, 88 were men and average age at surgery was 65.8 years (standard deviation, 9.8; range, 33 to 82 years). Full clinicopathologic information was gathered before and after surgery, including patient characteristics, treatment, combined clinical and surgical staging results (preoperative staging by computed tomography scan, selective mediastinoscopy, and systematic lymph node sampling at operation), histologic subtype, tumour grade, and survival data. Patients were divided into two groups: above median survival (AMS) (mean \pm SEM 84.0 \pm 5.1 months) and below median survival (BMS) (mean \pm SEM $10.8 \pm 0.8$ months). Macrophage-associated TNF $\alpha$ expression has been described previously in 26 of these patients [25]. Patient characteristics are shown in Table 1.

\section{Table 1: Patient Characteristics.}

\begin{tabular}{|c|c|c|}
\hline Characteristic & $\begin{array}{c}\text { Extended } \\
\text { Survival }\end{array}$ & Poor Survival \\
\hline No. of patients & 67 & 66 \\
\hline Age - years & $66.3 \pm 1.2$ & $65.3 \pm 1.2$ \\
\hline Male sex - no. (\%) & $39(58)$ & $49(74)$ \\
\hline \multicolumn{3}{|l|}{ Year of surgery - no. (\%) } \\
\hline 1991 & $0(0)$ & $5(7)$ \\
\hline 1992 & $5(7)$ & $6(9)$ \\
\hline 1993 & $6(9)$ & $4(6)$ \\
\hline 1994 & $6(9)$ & $7(11)$ \\
\hline 1999 & $50(75)$ & $44(67)$ \\
\hline \multicolumn{3}{|l|}{ Tumour stage - no. (\%) } \\
\hline 1 & $40(60)$ & $20(30)$ \\
\hline 2 & $18(27)$ & $19(29)$ \\
\hline $3 a$ & $9(13)$ & $23(35)$ \\
\hline $3 b$ and 4 & $0(0)$ & $4(6)$ \\
\hline \multicolumn{3}{|l|}{ Histology - no. (\%) } \\
\hline Squamous & $39(58)$ & $29(44)$ \\
\hline Adenocarcinoma & $19(28)$ & $23(35)$ \\
\hline Large cell & $4(6)$ & $8(12)$ \\
\hline Other & $5(7)$ & $6(9)$ \\
\hline \multicolumn{3}{|l|}{ Tumour Grade - no. (\%) } \\
\hline Well & $5(7)$ & $2(3)$ \\
\hline Moderate & $31(46)$ & $17(26)$ \\
\hline Poor & $30(45)$ & $46(70)$ \\
\hline Not recorded & $1(1)$ & $1(1)$ \\
\hline Adjuvant Chemotherapy (\%) & $0(0)$ & $2(3)$ \\
\hline Radiotherapy (\%) & $8(12)$ & $12(18)$ \\
\hline Palliative Radiotherapy (\%) & $7(10)$ & $9(14)$ \\
\hline Survival - months & $84.0 \pm 5.1$ & $10.8 \pm 0.8$ \\
\hline
\end{tabular}

Plus-minus values are means \pm SEM 


\section{Immunohistology}

Specimens studied were formalin fixed and paraffin embedded. Only blocks containing the advancing edge of the primary tumour were evaluated. Tissue sections of 4 $\mu \mathrm{m}$ thickness were cut onto glass slides and then dewaxed in xylene and rehydrated through graded alcohols. Antigen retrieval was carried out using Trilogy Antigen Retrieval solution (Cell Marque, Hot Springs, United States of America) in a pressure cooker (heated to $117.5^{\circ} \mathrm{C}$ for $1 \mathrm{~min}$ and then cooled to $100^{\circ} \mathrm{C}$ for $30 \mathrm{sec}-$ onds). TNF $\alpha$ mouse antihuman antibody was used (clone P/T2; Abcam, Cambridge, United Kingdom). Immunostaining was performed and TNF $\alpha$ was developed with peroxidase and 3,3'-diaminobenzidine tetrahydrochloride (brown reaction product). Sections were then counterstained with haematoxylin and mounted in an aqueous mounting medium (BDH Chemicals Ltd, Poole, United Kingdom). Appropriate isotype controls were performed where the primary antibodies were replaced by irrelevant mouse $\mathrm{mAb}$ of the same isotype and at the same concentration as the specific primary mAb. To assess whether $\mathrm{TNF} \alpha+$ cells were localised to mast cells, a double-stain technique described previously by us was used $[25,26]$, with the mouse monoclonal antibody to human tryptase (clone AA1, Dako Cytomation, Ely, Cambridgeshire, United Kingdom) employed to identify mast cells.

\section{Analysis and Validation of Immunostaining}

Analysis was performed blind with respect to the clinical outcome. The ten most representative high-power fields (x400) per slide were manually selected using an Olympus BX50 microscope (Olympus, Southall, United Kingdom). The respective areas of stroma and tumour islets were then measured at $x 400$ magnification using Analysis imaging software (Soft Imaging System $\mathrm{GmbH}$ ). The number of nucleated cells with positive staining for TNF $\alpha$ in each area were then counted manually and expressed as cells $/ \mathrm{mm}^{2}$ of stroma or tumour islets. Analysis was repeated for 20 patients to assess repeatability and validity.

\section{Statistical Analysis}

Statistical analyses were carried out using the GraphPad Prism software package (v. 4.02; GraphPad Prism Software Inc, San Diego, CA). For categoric analysis, the median value was used as a cut point to dichotomise the series. The $X^{2}$ test was used to test for relationships between categoric variables, and the Mann-Whitney nonparametric test was used to compare categoric with continuous variables. The Kruskal-Wallis one-way analysis of variance test was used to compare multiple groups. Kaplan-Meier survival curves were used to look for correlations with survival and were compared with the use of the log-rank statistic. For the above comparisons, $\mathrm{p}<0.05$ was considered statistically significant. A multivariate Cox proportional hazards model was used to estimate adjusted hazard ratios, $95 \%$ CIs, and to identify which of the macrophage markers were independent prognostic factors using the Statistical Package for the Social Sciences (SPSS, v. 13.0; SPSS Inc, Chicago, IL). The validity of the proportional hazards assumption was assessed from $\log (-\log [$ Survival $])$ curves.

\section{Results}

\section{Patient Characteristics}

Patent characteristics are shown in Table 1. Of the 133 patients studied, 110 had died at the time of analysis. Thirty-day mortality for the cohort was $4 \%$ and patients who died within the first 60 days of surgery were not included in this analysis. Sixty-eight tumours were squamous, 42 adenocarcinoma, 12 large cell, and 11 other. Sixty were stage I, 37 stage II, 32 stage IIIa, and four stage IIIb or IV. Two patients had additional postoperative chemotherapy and 20 had additional radiotherapy, 16 of whom had it for later palliation. Neither had any effect on survival. The overall 5-year survival was $31.3 \%$.

\section{Validation of Analysis}

Clear and distinguishable staining was evident for TNF $\alpha$ (Figure 1). Appropriate isotype controls were negative. In order to assess the validity of the method, area measurements and cell counts were repeated and intraclass correlation coefficients calculated. Good correlations were found for both: 0.997 (95\% CI, 0.996 to $0.998, \mathrm{p}<0.001$ ) and 0.994 ( $95 \% \mathrm{CI}, 0.992$ to $0.996, \mathrm{p}<0.001)$. This method of analysis has also been validated by our group previously [26].

\section{Cellular Distribution}

There was increased expression of TNF $\alpha$ in the tumour islets of patients with AMS compared to those with BMS (median 27.2 versus 18.8 cells $/ \mathrm{mm}^{2}$ respectively, $\mathrm{p}=$ 0.006). There was no significant difference in the expression of stromal TNF $\alpha$ between the two groups (AMS 23.8 versus $\mathrm{BMS} 16.8$ cells $/ \mathrm{mm}^{2}, \mathrm{p}=0.31$ ) (Figures $2 \mathrm{~A}$ and 2B).

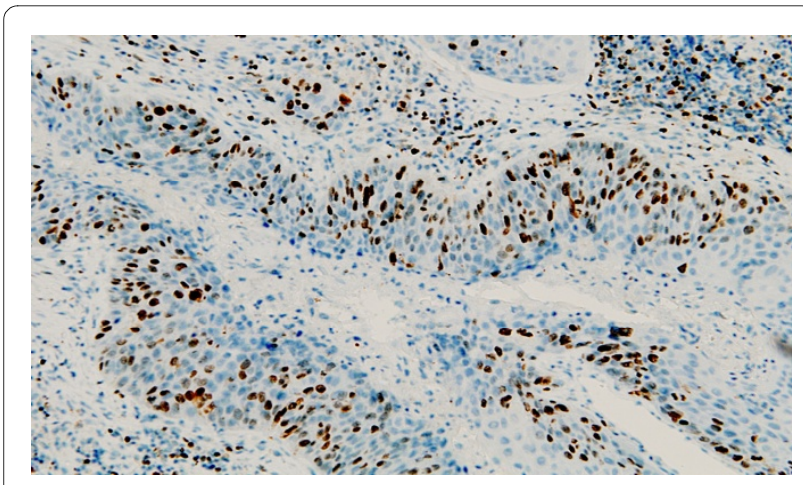

Figure 1 Immunohistology demonstrating positive TNFa expression (brown). Magnification $\times 100$. 


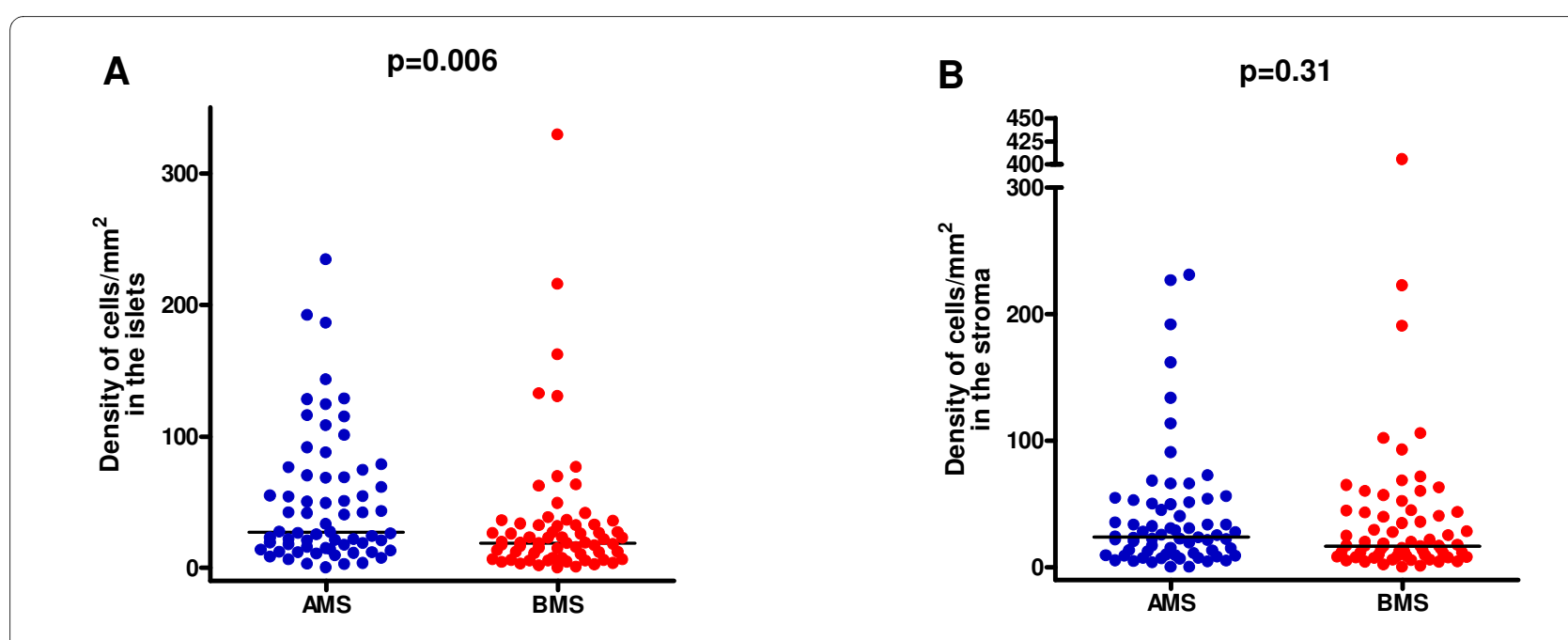

Figure 2 TNFa densities in Above Median Survival (AMS) and Below Median Survival (BMS) patients in the tumour islets (A) and stroma (B).

\section{Clinical Outcome}

Scatter plots of the raw data of TNF $\alpha$ density versus survival are shown in Figure 3. Spearman's rank correlation coefficient was calculated to assess any potential relationship with survival. A direct relationship between tumour islet TNF $\alpha$ density and survival was noted $\left(\mathrm{r}_{\mathrm{s}}=0.213, \mathrm{p}=\right.$ $0.01)$. No significant relationship was seen between survival and stromal TNF $\alpha$ density $\left(r_{\mathrm{s}}=-0.01, \mathrm{p}=0.90\right)$.

\section{Kaplan-Meier Survival Analysis}

For further analysis, the data were divided into two or three equal groups according to TNF $\alpha$ density. KaplanMeier survival curves were plotted and the log-rank statistic used to compare survival rates. When looking at two groups separated by the median, there was a non-significant trend for improved survival with above median TNF $\alpha$ expression in the tumour islets $(\mathrm{p}=0.15$, not shown). When divided into tertiles, there was significantly improved survival in the top tertile of TNF $\alpha$ expression in the tumour islets compared to the middle and lower tertiles (Figure 4A). Thus patients with high islet TNF $\alpha$ expression (upper tertile) were noted to have a significantly higher 5-year predicted survival as opposed to patients with low TNF $\alpha$ expression (lower tertile) (43\% versus $22 \%, \mathrm{p}=0.01)$. There was no significant relationship between TNF $\alpha$ expression in the stroma and survival (Figure 4B). Similar differences in survival with respect to TNF $\alpha$ expression in the tumour islets were also evident within tumour stages (Figure 5), although the differences did not reach statistical significance due to the smaller numbers within each stage. Interestingly, patients with stage IIIa disease in the top tertile of islet TNF $\alpha$ expression had a 5 year survival of $25 \%$ compared to $26 \%$ survival for those patients with stage I disease in the lower tertile of islet TNF $\alpha$ expression.

\section{Multivariate Cox Proportional Hazards Analysis}

A Multivariate Cox Proportional Hazards model was used to estimate adjusted hazard ratios, 95\% CIs, and to assess whether TNF $\alpha$ islet or stromal counts were independent prognostic factors, using a forward stepwise
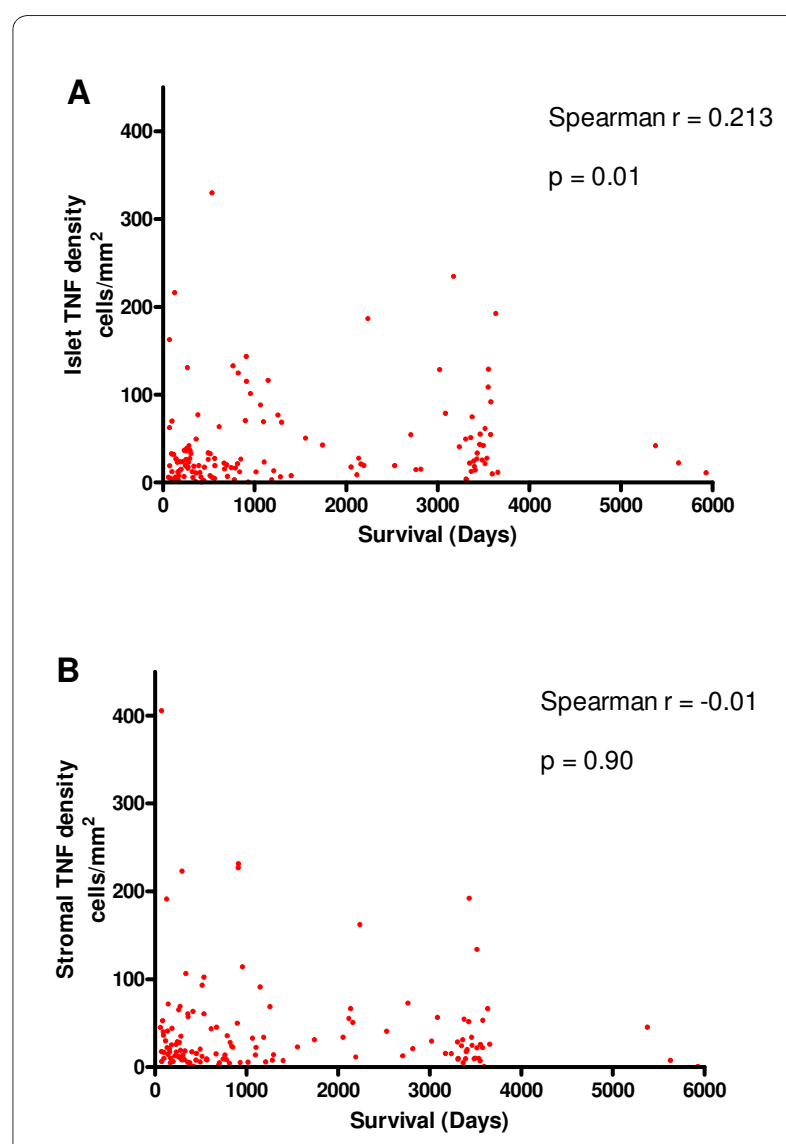

Figure 3 Raw data of cell counts expressing TNFa plotted against survival in days in the tumour islets (A) and stroma (B). 

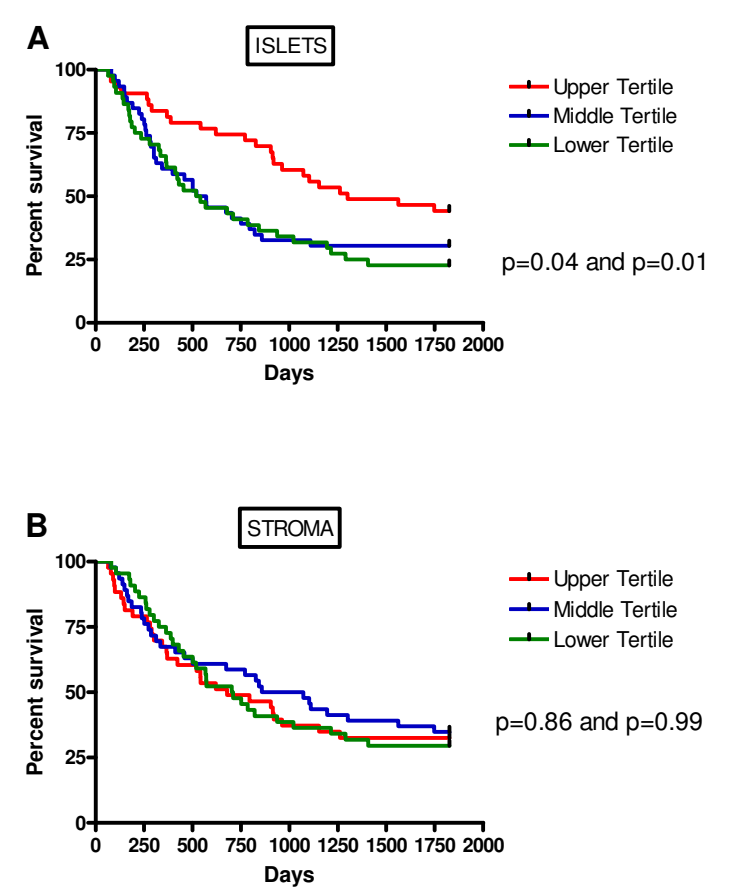

Figure 4 Kaplan-Meier five year survival curve for TNFa densities in the tumour islets (A) and stroma (B) divided into high counts (upper tertile), midrange counts (middle tertile) and low counts (lower tertile). The p values in (A) and (B) reflect the difference between the upper tertile and middle tertile groups and also the difference between the upper and lower tertile groups.

method with a probability of 0.05 for entry and 0.10 for removal by likelihood ratio statistics. Results of the multivariate analysis are shown in Table 2 . Continuous variables were used for islet and stromal TNFa. For every increase of 1 in the value of the variable, the hazard increases by the value of the hazard ratio. Expression of TNF $\alpha$ in the tumour islets emerged as a significant independent predictor of survival (hazard ratio 0.995, 95\% CI 0.989 to $1.000, \mathrm{p}=0.048$ ). Surprisingly, expression of TNF $\alpha$ in the tumour stroma emerged as a significant independent predictor of reduced survival (hazard ratio $1.007,95 \%$ CI 1.002 to $1.011, \mathrm{p}=0.007)$. There was no evidence of violation of the proportional hazards assumption.

\section{Cellular localisation of TNFa}

We have shown previously that in patients with extended survival, there is increased expression of macrophages in the tumour islets compared to patients with poor survival [26], and that in a separate study the majority of tumour islet macrophages expressed TNF $\alpha$ [25]. Macrophages accounted for approximately $60 \%$ of the TNF $\alpha+$ cells in the extended survival patients. While there was a marked

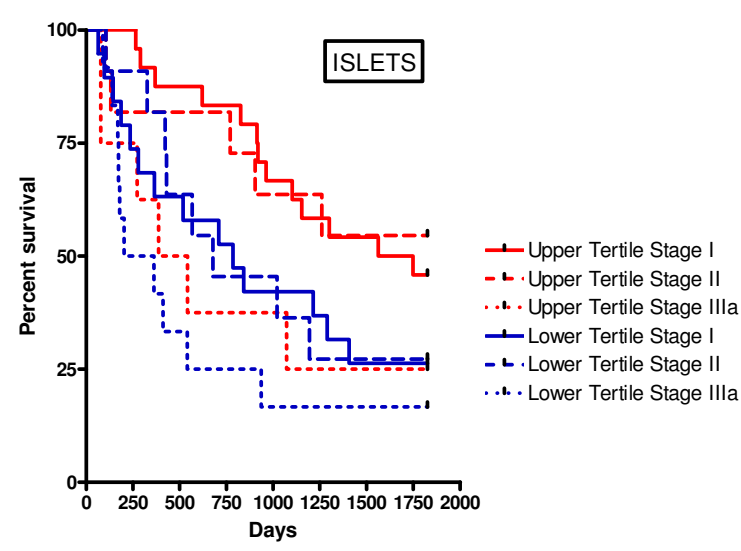

Figure 5 Kaplan-Meier five year survival curve for TNFa densities in the tumour islets for each tumour stage using upper and lower tertile values for TNFa density. For comparison of upper tertile stage I versus lower tertile stage I $p=0.06$, for upper tertile stage II versus lower tertile stage $\| p=0.18$, for upper tertile stage Illa versus lower tertile stage IIIa $p=0.55$, and for upper tertile stage Illa versus lower tertile stage $\mid p=0.70$.

difference in the number of TNF $\alpha+$ macrophages between extended survival and poor survival islets [25], it is evident from Figure 2 that the difference in total TNF $\alpha$ expression in this cohort of 133 patients is not so marked. Based on morphology, it was considered that a proportion of the TNF $\alpha+$ cells that were not macrophages may be mast cells. We therefore analysed the cellular distribution of TNF $\alpha$ expressed by mast cells (Figure 6) in the subset of samples previously stained for macrophageTNF $\alpha$ (AMS $[\mathrm{n}=20]$ and BMS [ $\mathrm{n}=20]$ ) [25]. In keeping with our previous observations [26], mast cell numbers were significantly increased in the islets of the AMS compared to BMS patients (medians 22.6 versus 0.7 cells/ $\left.\mathrm{mm}^{2}, \mathrm{p}<0.001\right)$. Interestingly, mast cells accounted for $45.2 \%$ of TNF $\alpha$ expression in the islets of the AMS patients, but only $5.2 \%$ of the BMS patients (Table 3$)(\mathrm{p}<$ 0.001 ). Thus taking macrophage and mast cell-associated $\mathrm{TNF} \alpha$ together, approximately $100 \%$ of islet TNF $\alpha$ was localized to mast cells or macrophages in the subset of AMS patients studied, while in the islets of the subset of BMS patients studied, only $28 \%$ of TNF $\alpha$ immunoreactivity was localized to these cells (Table 3$)(\mathrm{p}<0.001)$. Similar results were evident in the tumour stroma (Table $3, \mathrm{p}$ $<0.001)$. This is interesting because it demonstrates that in BMS patients, there is robust TNF $\alpha$ expression by cells other than macrophages and mast cells. These cells were predominantly mononuclear cells and rarely tumour epithelial cells. This suggests that TNF $\alpha$ is highly beneficial only when localized to macrophages and mast cells in tumour islets, and not when expressed by other cell types. 
Table 2: Results of Cox Regression Analysis.

\begin{tabular}{|c|c|c|c|}
\hline Factor & Hazard Ratio & $95 \% \mathrm{Cl}$ & $\mathbf{p}$ \\
\hline Islet TNFa & $0.995^{*}$ & 0.989 to 1.000 & $0.048 \dagger$ \\
\hline Stromal TNFa & $1.006^{*}$ & 1.002 to 1.011 & $0.007 \dagger$ \\
\hline Age & 1.022 & 1.000 to 1.043 & $0.049 \dagger$ \\
\hline Pathological stage & & & $0.002 \dagger$ \\
\hline I & 1.000 & & \\
\hline$\|$ & $0.283 \ddagger$ & 0.077 to 1.035 & 0.056 \\
\hline Illa & 0.373 & 0.102 to 1.372 & 0.138 \\
\hline IIIb and IV & 0.712 & 0.194 to 2.619 & 0.609 \\
\hline Grade - differentiated & & & $0.078 \dagger$ \\
\hline Well & 1.000 & & \\
\hline Moderate & $0.481 \S$ & 0.177 to 1.306 & 0.151 \\
\hline Poor & 0.752 & 0.488 to 1.159 & 0.197 \\
\hline Histology & & & 0.711 \\
\hline Squamous & 1.000 & & \\
\hline Adenocarcinoma & 0.708 & 0.323 to 1.553 & 0.389 \\
\hline Large & 0.828 & 0.363 to 1.891 & 0.654 \\
\hline Other NSCLC & 0.621 & 0.235 to 1.640 & 0.336 \\
\hline
\end{tabular}

${ }^{*}$ Continuous variable used. For every increase of 1 in the value of the variable, the hazard increases by the value of the hazard ratio.

† Overall significance as a prognostic factor

₹ Hazard relative to stage I

$\S$ Hazard relative to well differentiated

१ Hazard relative to squamous

Table 3: Assessment of the percentage of cell types expressing TNFa in patients with NSCLC in above median survival patients in the islets (AMSI) and stroma (AMSS) and below median survival patients in the islets (BMSI) and stroma (BMSS).

\begin{tabular}{|c|c|c|c|c|}
\hline & AMSI & AMSS & BMSI & BMSS \\
\hline$\%$ of cells which were Macrophages & $\begin{array}{c}61.8^{*} \\
(9.4-100)\end{array}$ & $\begin{array}{c}76.9+ \\
(16.6-100)\end{array}$ & $\begin{array}{c}22.2 \\
(5-71.5)\end{array}$ & $\begin{array}{c}39.7 \\
(0-61.9)\end{array}$ \\
\hline$\%$ of cells which were mast cells & $\begin{array}{c}45.2 \# \\
(20.3-58.4)\end{array}$ & $\begin{array}{c}54.99 \\
(0-79.1)\end{array}$ & $\begin{array}{c}5.6 \\
(0-100)\end{array}$ & $\begin{array}{c}10.5 \\
(0-55)\end{array}$ \\
\hline Estimated $\%$ of other cell types & 0 & 0 & 72 & 50 \\
\hline
\end{tabular}

${ }^{*} p<0.001$ compared to BMSI; $+p<0.001$ compared to BMSS; $\# p<0.001$ compared to BMSI; $9 p<0.001$ compared to BMSS. We analysed the cellular distribution of TNFa expressed by mast cells in the subset of samples previously stained for macrophage-TNFa [25]. 


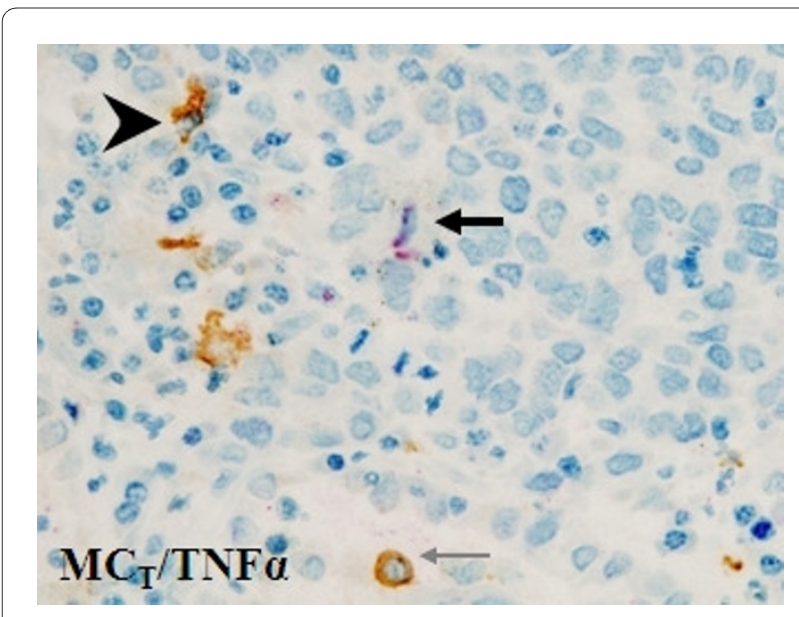

Figure 6 Mast cell immunohistochemical double-staining tryptase (brown) and TNFa (red) demonstrating the presence of TNFa in tryptase + mast cells. Arrowhead $=$ double-stain cell. Black arrow $=$ single-stain red cell. Grey arrow $=$ single-stain brown cell.

\section{Discussion and Conclusions}

The purpose of this study was to investigate the relationship between the microanatomical expression of TNF $\alpha$ and survival in surgically resected NSCLC. The results demonstrate that expression of TNF $\alpha$ in the tumour islets is associated with a significant increase in 5-year survival, independently of other favorable prognostic factors including stage, and that TNF $\alpha$ expression in the stroma is an independent predictor of reduced survival.

The role of TNF $\alpha$ in tumour biology remains controversial with both pro-tumourigenic and anti-tumourigenic properties identified [8-10,21,27]. Two small previous studies of patients with NSCLC suggested TNF $\alpha$ expression had little relationship to clinical outcome, but these did not distinguish between expression in tumour stroma and epithelial islets. The biology of these two tumour compartments demonstrates profound differences in matrix composition, cellular content and vascularity. Our previous studies [25,26] have demonstrated the importance of anatomical microlocalisation in terms of potential sites for cytotoxicity against tumours. The key findings of these studies was that tumour epithelial islets are the likely site of host cytotoxic responses against tumour progression because patients with extended survival have infiltration of their tumour islets with mast cells and macrophages $[25,26]$. Many cytokine-dependent effects are mediated through localized cell-cell contact, including the presentation of membrane-bound TNF $\alpha$ to TNF $\alpha$-receptor + cells [28]. The effects of cytokines including TNF $\alpha$ on tumour stroma versus islets are therefore likely to vary profoundly depending on the site of release, and the cell-cell interactions between TNF $\alpha$-producing cells and the cells they interact with. We therefore analysed TNF $\alpha$ expression with close attention to expression in the stroma versus the tumour islets.

In keeping with biological relevance of this concept, patients with AMS survival had greater immunoreactive TNF $\alpha$ expression in their tumour islets compared to those with BMS, and there was a positive correlation between increasing islet TNF $\alpha+$ cell density and survival. In addition, when our patient cohort was divided into tertiles according to islet TNF $\alpha+$ cell density we observed that patients with high expression (upper tertile) had significantly improved 5-year survival. Thus increasing expression of TNF $\alpha$ in the tumour islets was associated with a significant increase in 5-year survival, independently of other favorable prognostic factors. Conversely, although the density of TNF $\alpha+$ cells in the stroma was similar in AMS and BMS patients, TNF $\alpha$ expression in the stroma emerged as an independent predictor of reduced survival following Cox regression analysis. These results indicate that the micro-anatomical location of TNF $\alpha$ expression is potentially critical in determining its role in tumour biology.

Tumour stage is a key determinant of survival following surgery for NSCLC [1]. We were able to show that the relationship between survival and islet TNF $\alpha$ expression was evident within tumour stages although due to the relatively small numbers for each stage the differences did not reach statistical significance. Patients with stage I disease survive longer than patients with stage IIIa disease [1]. However, when tumour islet TNF $\alpha$ expression was compared by stage with respect to survival, it was of note that patients with stage IIIa NSCLC and high TNF $\alpha$ expression had a 5 -year survival of $25 \%$, comparable to that of stage I NSCLC patients with low TNF $\alpha$ expression, who had a 5-year survival of 26\%. Conversely, patients with stage I NSCLC and high TNF $\alpha$ expression have a 5 -year survival of $46 \%$. This suggests that TNF $\alpha$ expression within tumour islets is therefore a key determinant of NSCLC survival within stage, even within early stage disease.

A striking observation from this study was the cellular distribution of TNF $\alpha$ immunoreactivity in the tumour islets of patients with extended survival compared to those with poor survival. The macrophages which infiltrate the tumour islets in NSCLC are predominantly of the M1 cytotoxic phenotype [25] which express TNF $\alpha$. We have extended this work in the current study and show that mast cells within the tumour islets also express TNFa. What is striking, however, is that in the subset of patients with extended survival, all TNF $\alpha$ islet immunoreactivity was accounted for by macrophages and mast cells. In the subset of patients with poor survival, TNF $\alpha$ expression in the islets was also evident, but was rarely present in mast cells or macrophages. Thus it is not only 
expression of TNF $\alpha$ in the tumour islets that is critical in determining survival, but perhaps more importantly, the type of cells which are expressing it.

The distinction of tumour islets versus stroma is important as there is evidence suggesting that TNF $\alpha$ located in the stroma contributes towards tumour proliferation via angiogenesis [29]. In support of this, although there was no difference in the stromal density of TNF $\alpha+$ cells in AMS versus BMS patients, increasing stromal TNF $\alpha$ expression emerged as an independent predictor of worse survival. Whether this is due to the effects of $\mathrm{TNF} \alpha$ on the stroma or a reflection of the inability of potentially beneficial TNF $\alpha$-expressing macrophages and mast cells to infiltrate the islets is not known. The latter could be explained by an inappropriate chemokine repertoire released by the tumour stroma or even by a physical barrier, such as a thickened basement membrane, between the stroma and tumour islets.

The results of this study add to our previous work and have important clinical implications. We have shown that the density of TNF $\alpha+$ cells in tumour islets is a predictor of extended survival in NSCLC following surgery. Its localization to macrophages and mast cells in the tumour islets is the key factor relating to improved prognosis, and it seems unlikely that anti-TNF $\alpha$ strategies will be beneficial to such patients. In contrast, in poor prognosis patients whose tumours contain relatively few TNF $\alpha+$ macrophages and/or mast cells, anti-TNF $\alpha$ strategies may be worthy of further study as stromal expression is an independent predictor of poor survival. In view of the marked microanatomical and immunological heterogeneity within the tumour microenvironment in NSCLC, it is essential that attention is paid to this principle in future immunomodulatory trials in this disease. Targeting subphenotypes of disease with immunopathology predicted to respond to the intervention may then lead to the development of better anti-neoplastic therapeutic strategies.

\section{Competing interests}

The authors declare that they have no competing interests.

\section{Authors' contributions}

CO carried out the immunohistochemical staining, slide analysis, statistical analysis and prepared the manuscript. AS assisted with microtomy and the immunohistochemical staining. RG carried out the statistical analysis. DW provided the samples for analysis and prepared the manuscript. PB conceived the study, participated in its design, coordination and analysis, and prepared the manuscript. All authors read and approved the final manuscript.

\section{Acknowledgements}

Funding for this study was provided by the James Maxwell Grant Prophit Fellowship awarded to Dr Chandra Ohri by the Royal College of Physicians, London, United Kingdom.

\section{Author Details}

'Institute for Lung Health, Glenfield Hospital, Leicester, UK, 2Department of Infection, Immunity and Inflammation, University of Leicester, UK and

3Department of Thoracic Surgery, Glenfield Hospital, Leicester, UK
Received: 27 January 2010 Accepted: 23 June 2010

Published: 23 June 2010

\section{References}

1. Mountain CF: Revisions in the International System for Staging Lung Cancer. Chest 1997, 111(6):1710-1717.

2. O'Byrne KJ, Dalgleish AG: Chronic immune activation and inflammation as the cause of malignancy. Br J Cancer 2001, 85(4):473-483.

3. Dalgleish AG, O'Byrne K: Inflammation and cancer: the role of the immune response and angiogenesis. Cancer Treat Res 2006, 130:1-38.

4. Mastroeni P, Villarreal-Ramos B, Hormaeche CE: Effect of late administration of anti-TNF alpha antibodies on a Salmonella infection in the mouse model. Microb Pathog 1993, 14(6):473-480.

5. Nakane A, Minagawa T, Kato K: Endogenous tumor necrosis factor (cachectin) is essential to host resistance against Listeria monocytogenes infection. Infect Immun 1988, 56(10):2563-2569.

6. Bazzoni F, Beutler B: The tumor necrosis factor ligand and receptor families. N Engl J Med 1996, 334(26):1717-1725.

7. Locksley RM, Killeen N, Lenardo MJ: The TNF and TNF Receptor Superfamilies: Integrating Mammalian Biology. Cell 2001 104(4):487-501.

8. Balkwill F: TNF-alpha in promotion and progression of cancer. Cancer Metastasis Rev 2006, 25(3):409-416.

9. Mocellin S, Rossi CR, Pilati P, Nitti D: Tumor necrosis factor, cancer and anticancer therapy. Cytokine Growth Factor Rev 2005, 16(1):35-53.

10. Bongartz T, Sutton AJ, Sweeting MJ, Buchan I, Matteson EL, Montori V: Anti-TNF antibody therapy in rheumatoid arthritis and the risk of serious infections and malignancies: systematic review and metaanalysis of rare harmful effects in randomized controlled trials. JAMA 2006, 295(19):2275-2285.

11. Furst DE, Schiff MH, Fleischmann RM, Strand V, Birbara CA, Compagnone $D$, et al: Adalimumab, a fully human anti tumor necrosis factor-alpha monoclonal antibody, and concomitant standard antirheumatic therapy for the treatment of rheumatoid arthritis: results of STAR (Safety Trial of Adalimumab in Rheumatoid Arthritis). J Rheumatol 2003, 30(12):2563-2571.

12. Keystone EC, Kavanaugh AF, Sharp JT, Tannenbaum H, Hua Y, Teoh LS, et al.: Radiographic, clinical, and functional outcomes of treatment with adalimumab (a human anti-tumor necrosis factor monoclonal antibody) in patients with active rheumatoid arthritis receiving concomitant methotrexate therapy: a randomized, placebocontrolled, 52-week trial. Arthritis Rheum 2004, 50(5):1400-1411.

13. Lipsky PE, van der Heijde DMFM, St Clair EW, Furst DE, Breedveld FC, Kalden JR, et al: Infliximab and Methotrexate in the Treatment of Rheumatoid Arthritis. N Engl J Med 2000, 343(22):1594-1602.

14. St Clair EW, van der Heijde DM, Smolen JS, Maini RN, Bathon JM, Emery P, et al: Combination of infliximab and methotrexate therapy for early rheumatoid arthritis: a randomized, controlled trial. Arthritis Rheum 2004, 50(11):3432-3443.

15. Stone JH, Holbrook JT, Marriott MA, Tibbs AK, Sejismundo LP, Min Yl, et al: Solid malignancies among patients in the Wegener's Granulomatosis Etanercept Trial. Arthritis Rheum 2006, 54(5):1608-1618.

16. van de Putte LBA, Atkins C, Malaise M, Sany J, Russell AS, van Riel PLCM, et al.: Efficacy and safety of adalimumab as monotherapy in patients with rheumatoid arthritis for whom previous disease modifying antirheumatic drug treatment has failed. Ann Rheum Dis 2004 63(5):508-516

17. Lees CW, Ironside J, Wallace WA, Satsangi J: Resolution of non-small-cell lung cancer after withdrawal of anti-TNF therapy. N Engl J Med 2008 359(3):320-321.

18. Brown ER, Charles KA, Hoare SA, Rye RL, Jodrell DI, Aird RE, et al:: A clinical study assessing the tolerability and biological effects of infliximab, a TNF-alpha inhibitor, in patients with advanced cancer. Ann Oncol 2008, 19(7):1340-1346.

19. Du Bois JS, Trehu EG, Mier JW, Shapiro L, Epstein M, Klempner M, et al:: Randomized placebo-controlled clinical trial of high-dose interleukin2 in combination with a soluble p75 tumor necrosis factor receptor immunoglobulin $\mathrm{G}$ chimera in patients with advanced melanoma and renal cell carcinoma. J Clin Oncol 1997, 15(3):1052-1062.

20. Tsimberidou AM, Waddelow T, Kantarjian HM, Albitar M, Giles FJ: Pilot study of recombinant human soluble tumor necrosis factor (TNF) receptor (p75) fusion protein (TNFR:Fc; Enbrel) in patients with 
refractory multiple myeloma: increase in plasma TNF alpha levels during treatment. Leuk Res 2003, 27(5):375-380.

21. Lejeune FJ, Ruegg C: Recombinant human tumor necrosis factor: an efficient agent for cancer treatment. Bull Cancer 2006, 93(8):E90-100.

22. Lejeune FJ, Lienard D, Matter M, Ruegg C: Efficiency of recombinant human TNF in human cancer therapy. Cancer Immun 2006, 6:6.

23. Boldrini L, Calcinai A, Samaritani E, Pistolesi F, Mussi A, Lucchi M, et al: Tumour necrosis factor-[agr] and transforming growth factor-[bgr] are significantly associated with better prognosis in non-small cell lung carcinoma: putative relation with BCL-2-mediated neovascularization. BrJ Cancer 2000, 83(4):480-486.

24. Tran TA, Kallakury BV, Ambros RA, Ross JS: Prognostic significance of tumor necrosis factors and their receptors in nonsmall cell lung carcinoma. Cancer 1998, 83(2):276-282.

25. Ohri CM, Shikotra A, Green RH, Waller DA, Bradding P: Macrophages within NSCLC tumour islets are predominantly of a cytotoxic M1 phenotype associated with extended survival. Eur Respir J 2009, 33(1):118-126.

26. Welsh TJ, Green RH, Richardson D, Waller DA, O'Byrne KJ, Bradding P: Macrophage and mast-cell invasion of tumor cell islets confers a marked survival advantage in non-small-cell lung cancer. J Clin Oncol 2005, 23(35):8959-8967.

27. Balkwill F: Tumor necrosis factor or tumor promoting factor? Cytokine \& Growth Factor Reviews 2002, 13(2):135-141

28. Chen G, Goeddel DV: TNF-R1 Signaling: A Beautiful Pathway. Science 2002, 296(5573):1634-1635.

29. Szlosarek P, Charles KA, Balkwill FR: Tumour necrosis factor-alpha as a tumour promoter. Eur J Cancer 2006, 42(6):745-750.

\section{Pre-publication history}

The pre-publication history for this paper can be accessed here: http://www.biomedcentral.com/1471-2407/10/323/prepub

doi: $10.1186 / 1471-2407-10-323$

Cite this article as: Ohri et al., Tumour necrosis factor-alpha expression in tumour islets confers a survival advantage in non-small cell lung cancer BMC Cancer 2010, 10:323

Submit your next manuscript to BioMed Centra and take full advantage of:

- Convenient online submission

- Thorough peer review

- No space constraints or color figure charges

- Immediate publication on acceptance

- Inclusion in PubMed, CAS, Scopus and Google Scholar

- Research which is freely available for redistribution

Submit your manuscript at www.biomedcentral.com/submit
C Biomed Central 